\title{
PLANO NACIONAL DE CONVIVÊNCIA FAMILIAR E COMUNITÁRIA E A PROTEÇÃO SOCIAL: A FAMÍLIA COMO ESPAÇO PRIORITÁRIO DE DESENVOLVIMENTO
}

\author{
Caroline Simionato, Juliene Áglio de Oliveira Parrão \\ Faculdades Integradas "Antônio Eufrásio de Toledo". Curso de Serviço Social, Presidente Prudente - SP. Pesquisa \\ realizada com fomento do CNPq. E-mail: carol-simionato@hotmail.com
}

\begin{abstract}
RESUMO
A presente pesquisa buscou apontar a importância do Plano Nacional de Promoção, Proteção e Defesa do Direito de Crianças e Adolescentes à Convivência Familiar e Comunitária (PNCFC) no desenvolvimento de crianças e adolescentes. Foi considerado o fato da criança e do adolescente serem pessoas em peculiar desenvolvimento e sujeitos de direitos. Para isso utilizamos o Plano Nacional de Convivência Familiar e Comunitária - PNCFC, o Estatuto da Criança e do Adolescente ECA, e outras legislações que prevê a proteção social. O método utilizado foi o materialista dialético, e a metodológica foi a pesquisa bibliográfica e a pesquisa de campo.
\end{abstract}

Palavras-chave: Crianças, Adolescentes, Convivência Familiar e Comunitária.

\section{NATIONAL PLAN FAMILY AND COMMUNITY AND SOCIAL PROTECTION: THE FAMILY AS PRIORITY} AREA DEVELOPMENT

\begin{abstract}
This research sought to highlight the importance of the National Plan for the Promotion, Protection and Defense of the Right of Children to Family and Community (PNCFC) in the development of children and adolescents. We considered the fact that children and adolescents are peculiar people in development and subject of rights. For this we used the National Plan for Family and Community Living - PNCFC, the Statute of Children and Adolescents - ECA, and other legislation providing for social protection. The method was dialectical materialism, and went to the methodological literature and field research.
\end{abstract}

Keywords: Children, Teens, Family and Community Living. 


\section{INTRODUÇÃO}

A situação de crianças e adolescentes que vivem fora de suas origens aumenta a cada dia no Brasil. São frequentes os casos de crianças e adolescentes abandonados, negligenciados, em situação de rua, ou em situação de drogadição.

A destituição do poder familiar acontece por uma série de fatores sociais, como o econômico, emocional e psicológico, como negligência, abandono e abuso, e representa o afastamento judicial da criança e/ou adolescente da família de origem. Tornase uma temática de importância a ser estudada se tratando de crianças e adolescentes que estão em processo de formação e necessitam de acompanhamento e efetivação de seus direitos para que os eventos não aconteçam de forma a obscurecer a infância ou adolescência plena.

Nos termos do Estatuto da Criança e do Adolescente (ECA - Lei no 8.069, de 13 de julho de 1990) considera-se criança a pessoa de até doze anos incompletos e, adolescente aquela entre doze e dezoito anos de idade. Segundo este, ainda, a criança e o adolescente gozam de todos os direitos fundamentais inerentes à pessoa humana, sem prejuízo da proteção integral, assegurando-lhes, por lei ou por outros meios, todas as oportunidades e facilidades, a fim de lhes facultar o desenvolvimento físico, mental, moral, espiritual e social, em condições de liberdade e dignidade, sendo dever da família, da comunidade, da sociedade em geral e do poder público assegurar, com absoluta prioridade, a efetivação dos direitos referentes à vida, à saúde, à alimentação, à educação, ao esporte, ao lazer, à profissionalização, à cultura, à dignidade, ao respeito, à convivência familiar e comunitária. Aos pais incumbe o dever de sustento, guarda e educação dos filhos, cabendo-Ihes ainda, no interesse destes, a obrigação de cumprir e fazer cumprir as determinações judiciais.

Quando as crianças e adolescentes tiveram seus direitos desatendidos ou violados, seja por uma situação de abandono social, seja pelo risco pessoal a que foram expostos pela negligência de seus responsáveis, o acolhimento é uma medida de proteção especial. Para aqueles que, em casos extremos, estão necessitando permanecer afastados de suas famílias ou responsáveis, até que condições adequadas de convivência se restabeleçam, devem encontrar nos espaços de acolhimento, um cuidado e proteção - a falta ou carência de recursos materiais não constitui motivo suficiente para a perda ou a suspensão do poder familiar.

Utilizando-se disso, o trabalho do profissional de Serviço Social é de fundamental importância nesse processo, pois é ele que vai intermediar e observar a 
correta execução dos papéis desempenhados pelos envolvidos (famílias, profissionais que atuam nas Instituições de acolhimento e pessoas que participam de Programas de Acolhimento).

\section{METODOLOGIA}

A metodologia utilizada para realização da pesquisa foi a bibliográfica e a pesquisa de campo. Através da pesquisa bibliográfica, foi possível utilizar literaturas para subsidiar a discussão sobre o acolhimento familiar e a proteção social, além de encontrar embasamento de caráter jurídico sobre o processo de acolhimento familiar e sobre a proteção social, além de poder contar com documentos federais que norteiam o objeto pesquisado. Por fim, foi realizada a pesquisa de campo, onde foi possível conhecer melhor a realidade do município de Presidente Prudente.

A técnica utilizada para realização das entrevistas foi a semiestruturada, onde elaboramos perguntas previamente para buscar direcionamento das entrevistas, porém, sem que isso acontecesse de forma fechada para que fosse possível reconhecer situações não previstas no questionário.

As entrevistas aconteceram em dois momentos. O primeiro com as duas técnicas assistentes sociais que fazem parte da Sociedade Civil Lar dos Meninos, a instituição que executa o trabalho de acolhimento e reintegração familiar há mais de um ano.

O segundo momento da pesquisa de campo, foi realizar entrevistas com três famílias acolhedoras, que são as famílias que ficam com as crianças que estão em supressão do poder familiar ou em processo de adoção. Ao total, são oito famílias acolhedoras, portanto a pesquisa foi realizada com $37,5 \%$ do universo pesquisado. As famílias foram escolhidas pela equipe técnica da instituição, onde posteriormente entrei em contato com elas.

A pesquisa realizada é de caráter qualitativo, visto que a temática abordada buscou reconhecer a qualidade e efetividade da rede de atendimento à criança e ao adolescente, e do Plano de Promoção, Defesa e Garantia do Direito de Crianças e Adolescentes à Convivência Familiar e Comunitária.

O objetivo da pesquisa visa discutir e buscar respostas para as hipóteses do acolhimento familiar como medida de proteção social e os aspectos que envolvem a problemática do afastamento, supressão ou destituição do poder familiar, a família acolhedora, de origem, extensa e outras configurações.

\section{RESULTADOS}

A família é considerada o espaço 
prioritário e possível de desenvolvimento da criança e do adolescente. De acordo com o Plano Nacional de Promoção, Proteção e Defesa do Direito de Crianças e Adolescentes à Convivência Familiar e Comunitária, a legislação brasileira vigente reconhece e preconiza a família, enquanto estrutura vital, lugar essencial à humanização e à socialização da criança e do adolescente, espaço ideal e privilegiado para o desenvolvimento integral dos indivíduos.

Conhecendo o quadro sócio histórico e cultural das famílias e crianças do nosso país, conseguimos identificar as representações negativas construídas diante das famílias com dificuldades. Essas situações são marcadas pelo forte paradigma da institucionalização, ou seja, por muito tempo - com resquícios até os dias de hoje - acreditou ser melhor retirar as crianças e adolescentes da família, do que fortalecer os vínculos, já que para a maioria da sociedade essas famílias eram incapazes, desconsiderando o problema estrutural que se encontra nas nossas relações sociais junto ao Estado.

De acordo com o Plano de Convivência Familiar e Comunitária, as questões expostas acima, são descritas da seguinte forma:

(...) a história social das crianças, dos adolescentes e das famílias revela que estas encontraram e ainda encontram inúmeras dificuldades para proteger e educar seus filhos. Tais dificuldades fora traduzidas pelo Estado em um discurso sobre uma pretensa "incapacidade" da família de orientar os seus filhos. Ao longo de muitas décadas, este foi $o$ argumento ideológico que possibilitou Poder Público o desenvolvimento de políticas paternalistas voltadas para o controle e a contenção social, principalmente para a população mais pobre, com total descaso pela preservação de seus vínculos familiares. Essa desqualificação das famílias em situação de pobreza, tratadas como incapazes, deu sustentação ideológica à prática recorrente da suspensão provisória do poder familiar ou da destituição dos pais e de seus deveres em relação aos filhos.

Outra problemática que envolve a cultura da institucionalização e que está presente em diversos estados até os dias de hoje, é a dos fatores econômicos, mais especificamente pela condição de pobreza, que acaba por separar crianças e adolescentes de suas famílias sob o argumento de proteção.

Portanto:

Essas representações negativas sobre as famílias cujos filhos formavam o público da assistência social e demais políticas sociais tornaram-se parte estratégica das políticas de atendimento, 
principalmente da infância e da juventude, até muito recentemente. (PLANO NACIONAL DE CONVIVÊNCIA FAMILIAR E COMUNITÁRIA, p.16, 2013).

Com isso, refletimos na importância da desconstrução de modelos criados no que diz respeito ao acolhimento institucional, e as famílias, que muitas vezes não se "enquadram" no padrão pré-estabelecido socialmente.

Os profissionais, assim como toda a sociedade, carecem refletir sobre a imposição social para que seja mantido um modelo de família, onde as dificuldades e vulnerabilidades vivenciadas são tidas como contexto para separação de crianças e adolescentes de suas famílias e comunidades, sem levar em consideração a capacidade protetiva das famílias, assim como, sua força positiva.

A família é uma instituição social essencial que contribui para a manutenção de todas as outras instituições. A instituição "família" é formada naturalmente através de relações e afetos que unem as pessoas e as fazem conviver em um mesmo ambiente, dividindo tarefas e prazeres.

A família é, ainda, dotada de autonomia, competências e geradora de potencialidades: novas possibilidades, recursos e habilidades são desenvolvidos frente aos desafios que se interpõem em cada etapa de seu ciclo de desenvolvimento. Como seus membros, está em constante evolução: seus papéis e organização estão em contínua transformação. Este ponto é de fundamental importância para se compreender o investimento no fortalecimento e no resgate dos vínculos familiares em situação de vulnerabilidade, pois cada família, dentro de sua singularidade, é potencialmente capaz de se reorganizar diante de suas dificuldades e desafios, de maximizar as suas capacidades, de transformar suas crenças e práticas para consolidar novas formas de relações. (p.30, 2013)

Com isso, finalizamos esse tópico reconhecendo a importância da aplicabilidade do Plano Nacional de Promoção, Proteção e Defesa do Direito de Crianças e Adolescentes à Convivência Familiar e Comunitária (PNCFC) no município de Presidente Prudente.

\section{DISCUSSÃO}

O Plano Nacional de Promoção, Proteção e Defesa do Direito de Crianças e Adolescentes à Convivência Familiar e Comunitária (PNCFC) é resultado do avanço no que tange aos direitos das crianças e adolescentes, preconizados pelo Estatuto da Criança e do Adolescente (ECA). Este Plano tem como principal objetivo efetivar o fortalecimento de vínculos familiares e 
comunitários com o intuito de garantir que as crianças e adolescentes possam vivem junto a seus próximos de forma a preservar seu pleno desenvolvimento.

Para que isso aconteça de forma concreta, é de extrema importância o investimento nas políticas públicas de atenção à família, considerando especificidades regionais, estaduais e municipais, assim como a consolidação e articulação com a rede de proteção de direitos de crianças e adolescentes, a reordenação dos serviços de Acolhimento Institucional, a implantação de Programas de Famílias Acolhedoras, entre outras ações enfatizadas no Plano Nacional de Promoção, Proteção e Defesa do Direito de Crianças e Adolescentes à Convivência Familiar e Comunitária.

Para que a legislação e marcos normativos e regulatórios do direito a convivência familiar e comunitária sejam inteiramente eficazes, é necessário que haja a mobilização do Estado e sociedade, ou seja, um movimento que busque promover a quebra de paradigmas no que diz respeito à institucionalização de crianças e adolescentes, e que possamos ver as crianças e adolescentes de forma indissociável do seu contexto familiar e comunitário.

As estratégias deste plano estão voltadas principalmente para a prevenção da quebra ou perda do vinculo familiar e comunitário e para a qualificação dos serviços de acolhimento e dos outros serviços da rede de atendimento e proteção dos direitos de crianças e adolescentes. Quando essa situação já é vivenciada pela família e comunidade, o investimento é para o retorno e convívio dos mesmos.

\section{CONCLUSÃO}

Através da pesquisa realizada com apoio financeiro do Conselho Nacional de Desenvolvimento Científico e Tecnológico (CNPq) em Iniciação Científica, foi possível perceber o quanto estão avançados os trabalhos realizados pela instituição de acolhimento Sociedade Civil Lar dos Meninos no que tange ao acolhimento familiar no que se refere ao Plano Nacional de Promoção, Proteção e Defesa do Direito de Crianças e Adolescentes à Convivência Familiar e Comunitária.

Porém, é importante reconhecer que apenas com a instituição supracitada, não é possível a efetivação concreta do plano, visto que, para isso seria necessário a participação de todos os atores que fazem parte da rede de proteção à criança e ao adolescente.

Através da pesquisa observamos também os desafios e avanços que ainda devem acontecer no acolhimento institucional e familiar no Município de Presidente Prudente. Entre eles, a articulação de rede que muitas vezes se mostra ineficaz 
enquanto política pública, e principalmente para a superação das violências, vulnerabilidades e riscos vivenciados pelas famílias dos acolhidos.

De acordo com as entrevistas realizadas por meio da pesquisa de campo, constatamos o avanço teórico político dos assistentes sociais da instituição, já que os mesmos se mostraram abertos as diversas configurações familiares, deixando de lado preceitos morais e religiosos.

Outro ponto importante para a pesquisa no que se refere aos profissionais, foi o fato de realmente acreditarem na reintegração familiar como medida protetora, e a adoção como medida excepcional, seguidas pelo Plano Nacional de Promoção, Proteção e Defesa do Direito de Crianças e Adolescentes à Convivência Familiar e Comunitária.

Em geral, a pesquisa confirmou a hipótese sobre o Plano Nacional de Promoção, Proteção e Defesa do Direito de Crianças e Adolescentes à Convivência Familiar e Comunitária como medida de proteção, e de grande importância para o desenvolvimento de crianças em situação de supressão ou destituição do poder familiar.

Outra hipótese confirmada é da necessidade do planejamento e articulação do fluxo de atendimento de crianças e adolescentes em situação de acolhimento, para que torne ainda mais possível a reintegração familiar.

\section{REFERÊNCIAS}

ARPINI, D. M. Repensando a Perspectiva Institucional e a Intervenção em Abrigos para Crianças e Adolescentes. Psicologia Ciência e Profissão, Santa Maria, v. 21, n. 3, p. 70-75, 2003.

BRASIL. Constituição (1988). Constituição da República Federativa do Brasil. Brasília, DF: Senado, 1988.

BRASIL. Lei 8.069, de 13 de julho de 1990. Dispõe sobre o Estatuto da Criança e do Adolescente e dá outras providências. Disponível em: <http://www.planalto.gov.br/ccivil_03/leis/L8 069.htm>. Acesso em: 15 jul. 2014.

BRASIL. Lei Orgânica da Assistência Social. Lei № 8.742, De 7 de Dezembro de 1993. Brasília, DF: Senado, 1993.

BRASIL. Plano Nacional de Promoção, Proteção e Defesa do Direito de Crianças e Adolescentes à Convivência Familiar e Comunitária. Brasília, DF, 2006.

SPOSATI, Aldaíza. Modelo brasileiro de proteção social não contributiva: concepções fundantes. Concepção e gestão da proteção social não contributiva no Brasil. -- Brasília: Ministério do Desenvolvimento Social e Combate à Fome, UNESCO, 2009.

Recebido para publicação em 13/08/2014 Revisado em 09/09/2014 Aceito em 19/09/2014 